\title{
Supervisão em Caps: \\ Uma Abordagem Psicanalítica
}

Supervision In Psychosocial

Centers For Mental Health:

A Psychoanalytic Approach

Supervisión En Caps:

Un Abordaje Psicoanalítico

Sonia Alberti

Universidade Estadual do

Rio de Janeiro

Analice de Lima

Palombini

Universidade Federal do

Rio Grande do Sul
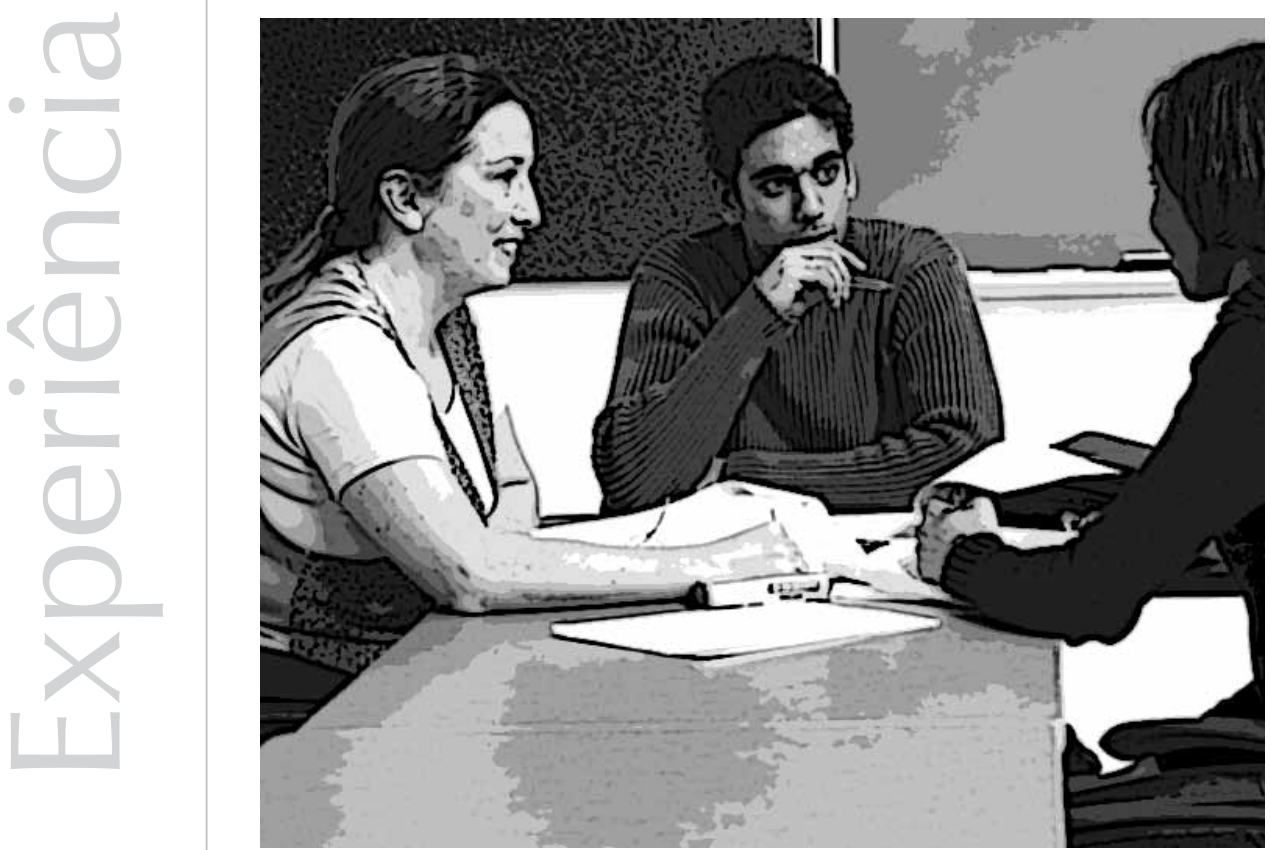
Resumo: Este artigo apresenta uma elaboração teórica de supervisão em CAPS, articulando duas experiências geograficamente distantes e levantando questões sobre essas supervisões sob orientação psicanalítica e conforme as diretrizes da política de saúde mental vigente no País. Após correlacioná-las com dados colhidos na literatura, discutem-se as principais contribuições no percurso dessas supervisões: a disponibilização de um espaço de fala, possibilitado a todos os seus participantes, um processo metodológico de construção e de sistematização dos saberes, maior entrosamento e autonomia das equipes e iniciativas de articulação em rede com o território na construção do projeto terapêutico do usuário. Visa-se, com isso, a uma contribuição possível da psicanálise ao campo da saúde mental na perspectiva da atenção psicossocial.

Palavras-chave: Psicanálise. Supervisão psicanalítica. Atenção psicossocial. Psicoterapia psicanalitica.

Abstract: This article is the result of some theoretical discussions in psychoanalysis about supervision in psychosocial centers for mental health. It begins with two geographically quite distant experiences, then raises the questions about these supervisions under the psychoanalytic orientation and articulates them with the guidelines as dictated by the national policies of mental health. Taking into account other experiences found in the bibliography, it then discusses the main contributions of both experiences: the possibility to create a field for every participant to speak, the specificity of the implied method which made it possible to construct and organize knowledge, greater involvement and autonomy teams, networking initiatives with the territory and construction of the therapeutic project of the users. The aim is, therefore, a possible contribution of psychoanalysis to the mental health field from the perspective of psychosocial care.

Keywords: Psychoanalysis. Psychoanalytic supervision. Psychosocial attention. Psychoanalytic psychotherapy.

Resumen: Este artículo presenta una elaboración teórica de supervisión en CAPS, articulando dos experiencias geográficamente distantes y levantando cuestiones sobre esas supervisiones bajo orientación psicoanalítica y conforme las directrices de la política de salud mental vigente en el País. Después de correlacionarlas con datos recogidos en la literatura, se discuten las principales contribuciones en el transcurso de esas supervisiones: la puesta a disposición de un espacio de hablar, posibilitado a todos sus participantes, un proceso metodológico de construcción y de sistematización de los saberes, mayor integración y autonomía de los equipos e iniciativas de articulación en red con el territorio en la construcción del proyecto terapéutico del usuario. Se visa, con eso, a una contribución posible del psicoanálisis al campo de la salud mental en la perspectiva de la atención psico-social.

Palabras clave: Psicoanálisis. Supervisión psicoanalitica. Atención psico-social. Psicoterapia psicoanalítica.

O texto que se segue é parte da elaboração que acompanhou duas experiências de supervisão em CAPS geograficamente distantes, que não deixam de apresentar questões afinadas com a prática hodierna da atenção psicossocial. Ambas as supervisões foram realizadas por psicanalistas, visando a uma contribuição possível da psicanálise às diretrizes atuais em saúde mental. Vale lembrar, de saída, que a supervisão clínico-institucional foi viabilizada como política de gestão, seja por iniciativa do Município, seja pelo Ministério da Saúde que, através da Portaria GM no 1174, de 07.07.05 (supervisão clínico-institucional dos CAPS e Rede de Atenção Psicossocial), vem sustentando a importância das supervisões de CAPS em todo o território nacional. A supervisão configura-se como relevante apoio ao redimensionamento dos serviços de saúde mental que o processo de reforma psiquiátrica, alavancado pela Lei Federal $\mathrm{n}^{\circ}$ 10.216, necessariamente requer, implicando "novos desafios clínicos, teóricos, políticos e, mesmo, profissionais" (Figueiredo, 2010, p.12). Os supervisores de CAPS que exercem sua função a partir da psicanálise não buscam "a prática de uma clínica analítica stricto sensu nesses serviços, mas, atravessados pelos referenciais analíticos, (...) sustentam uma prática que tome o sujeito, e suas escolhas, como o eixo de um trabalho clínico" (Rinaldi \& Burstzyn, 2006). Com efeito, um legado fundamental de Freud que importa operar no contexto desses serviços diz respeito à "idéia de que a subjetividade se constitui na relação a uma alteridade; (...) não transparente 
1"Núcleo como uma aglutinação de conhecimentos e como a conformação de um determinado padrão concreto de compromisso com a produção de valores de uso. $\mathrm{O}$ núcleo demarcaria a identidade de uma área de saber e de prática profissional, $\mathrm{e}$ o campo, um espaço de limites imprecisos onde cada disciplina e profissão buscariam em outras apoio para cumprir suas tarefas teóricas e práticas" (Campos, 2000, p.220). De acordo com essa concepção, núcleo e campo são mutantes e se influenciam reciprocamente não sendo possível estabelecer limites precisos entre um e outro. "Contudo, no núcleo, haveria uma aglutinação de saberes e práticas, compondo uma certa identidade profissional e disciplinar" (Campos, 2000, p.221) a si mesma, que não se deixa apreender integralmente por um saber, guardando uma dimensão inconsciente de resistência que não se deixa capturar" (Palombini, 2006, p. 121; 2007, p.136).

As supervisões operaram com foco em três eixos fundamentais. Em primeiro lugar, na articulação com o território: no primeiro CAPS, que identificaremos doravante como CAPS A, tendo em vista sua história recente, urgia verificar a otimização da articulação do serviço com o Município, em especial com a rede de atenção psicossocial da qual pudesse lançar mão, e orientar os trabalhos no sentido de assim se integrarem à política de saúde mental. No segundo CAPS, que identificamos como CAPS B, ao contrário, o fato de se tratar do mais antigo da cidade o fazia carregar uma história já cristalizada de relações pouco produtivas com outros serviços e setores do território, tendo sido preciso desconstruir os pré-julgamentos com respeito a essas relações a fim de reconstruí-las sobre novas bases.

Em segundo lugar, com vistas à orientação clínica: as equipes assistenciais, ou parte delas, carecem, muitas vezes, de uma orientação teórico-clínica, o que, se não as impede de se mostrarem bastante preocupadas com as vicissitudes diagnósticas e a direção do tratamento dos usuários que acompanham cotidianamente, deixa-as muitas vezes sem recursos para conter um momentâneo agravamento do quadro clínico ou para lidar da melhor forma com suas consequências. Em nossa experiência, a proposta de supervisão seguiu uma orientação teórica e técnica ancorada na psicanálise, com base na literatura já existente (por exemplo, Alberti \& Figueiredo, 2006), sem perder de vista o contexto em que se insere: trata-se da tomada em consideração de um caso clínico singular, em acompanhamento por uma equipe multiprofissional, que intenta um trabalho interdisciplinar articulado a uma rede intersetorial.
Em terceiro lugar, no fortalecimento dos laços nas equipes para uma melhor atenção ao usuário. Articulada ao trabalho clínico e, ao mesmo tempo, à política de saúde mental, essa integração, que é o corolário de uma supervisão clínico-institucional, deve levar em conta, por um lado, os diferentes níveis das funções que exercem os membros da equipe e as especificidades de cada núcleo profissional em relação, e, por outro lado, o que compõe o campo comum da saúde mental (conforme a distinção entre campo e núcleo, proposta por Campos, Chakour e Santos, 1997, Campos, 200011). Ainda, é preciso compor os modos de trabalhar em equipe com o estilo, a singularidade de cada um de seus integrantes, de forma que cada um possa encontrar sua maneira de se engajar no projeto terapêutico do serviço.

O fato é que o dia a dia nos serviços de atenção psicossocial exige levar em conta múltiplos fatores, de forma que não se pode simplesmente reduzir o trabalho ao acompanhamento clínico dos usuários que procuram o serviço ou que já estão inseridos nele. A multiplicidade abrange desde a macropolítica até os fatores econômicos, passando por aspectos das relações entre as pessoas, os laços sociais, e, finalmente, as dificuldades de cada ser falante concernentes à castração. O trabalhador de saúde mental sofre a influência desses fatores tanto quanto as pessoas a quem dirige seus cuidados. Não se trata, portanto, simplesmente de verificar em que bases teóricas se dão as práticas de cuidado nos CAPS. Como norte, tomamos a ética na qual nos situamos (cf. Lacan, 1988/1986, e Rinaldi, 1997), ou seja, a ética da psicanálise, que nos orienta a instigar o outro a produzir - e a reconhecer como seu - um saber sobre sua relação com aquilo de que, antes, se queixava, ética, então, que leva à produção, mas pela via do dizer: bem dizer a relação que o sujeito tem com a prática que desenvolve. 
Passemos, assim, às particularidades dessas experiências.

\section{A resistência à mudança}

No ano anterior ao projeto de supervisão no CAPS A, várias foram as mudanças sofridas pelo serviço devido a maior preocupação em adequar sua proposta às portarias ministeriais quanto às ações estratégicas para a saúde mental no País. Essas mudanças eram tanto políticas quanto geográficas. Iniciara-se um processo de municipalização cujas discussões vinham se estendendo há três anos - até então, era um serviço diretamente ligado à capital do Estado, a qual recebia muito bem os usuários de saúde mental em diversos dos seus lugares públicos de cultura e de lazer. Dizia-se que era um CAPS aberto: os pacientes vinham para seus atendimentos, saíam pela cidade, frequentavam a praça, os bancos, o comércio, até mesmo os motéis, integrando-se com o cotidiano e sendo bem aceitos pela comunidade de forma geral. Desde cedo, o CAPS, que abrigava as reuniões da ONG Núcleo da Luta Antimanicomial do Estado, viu-se identificado com as novas orientações no trabalho com a saúde mental.

A iminência da municipalização do CAPS, com a consequente saída do centro da capital, levou a vários movimentos, tanto de técnicos quanto de usuários: abaixo-assinado protocolado e entregue diretamente ao Secretário Estadual de Saúde, clamor nas rádios, por iniciativas diversas dos usuários, idas espontâneas, também dos usuários, ao gabinete do Secretário de Saúde. O fato é que o prédio que o CAPS ocupava já estava sendo esvaziado para ser demolido, em função de ter sido condenado pelo corpo de bombeiros...

Alguns usuários aceitaram a perspectiva da mudança, mas outros, não, e isso começou a interferir no próprio quadro clínico dos pacientes, suscitando resistências as mais variadas. O serviço ficou muito vulnerável, surgiram muitas crises, até mesmo suicídios e tentativas de suicídio, que marcaram para sempre o CAPS. Podemos dizer, sem dúvida, que houve uma comoção, inclusive na equipe.

Eis a razão de um primeiro momento de trabalho, a partir de um contato da coordenação com a supervisora, o que iria levar ao projeto de supervisão no ano seguinte e permitiria elaborar os primeiros impasses. O CAPS pôde mudar-se, vindo a ocupar um prédio com uma estrutura física muito melhor que a anterior, e, apesar de ser um local ao qual os antigos usuários se dirigiam exclusivamente para seus atendimentos por não mais estar em seu território original -, integrou-se ao novo Município e iniciou projetos de articulação com a rede de saúde mental local visando a parcerias, tendo em vista os novos usuários da região. Essa foi, na realidade, apenas mais uma das mudanças impostas à equipe e aos usuários, ao longo dos onze anos de existência do serviço.

Mas era urgente falar dos problemas. No primeiro dia de supervisão, cada participante tomou a palavra para se apresentar e aproveitou para fazer comentários sobre a história da instituição, desde o momento em que passou a fazer parte dela, a qual resumimos abaixo:

1) o serviço se constituiu a partir da associação, em uma equipe multidisciplinar, de profissionais que vieram de várias clínicas, sem que tivesse havido qualquer preparo anterior, de maneira que muitos nunca haviam trabalhado antes com saúde mental;

2) foi formado inicialmente um ambulatório de saúde mental sem que muitos de seus técnicos tivessem qualquer formação adicional para isso; 
3) passou a ser CAPS em 2002, mas ligado à Secretaria de Saúde do Estado;

4) em julho de 2007, em decorrência da condenação do prédio, foi alocado em outro Município - pois já existia um CAPS municipal na capital -, sendo então municipalizado.

Evidentemente, todas essas mudanças mobilizaram diversas resistências por parte de todos os participantes que, sem consulta prévia, ficaram sem opção, tendo que acatar o remanejamento. Tratar disso foi o primeiro trabalho realizado pela supervisão. Em reunião de supervisão, cada membro da equipe pôde tecer suas observações sobre o assunto, e as dificuldades para a mudança puderam ser pontuadas e percebidas a partir de um novo ponto de vista.

\section{Quando uma supervisão abre a possibilidade para Scilicet: todos podem saber}

Para além do problema das mudanças múltiplas, foram fundamentalmente duas as questões imediatamente detectadas quanto a possíveis disfunções desse CAPS - e que provocaram problemas clínicos graves, como os suicídios já mencionados. A primeira poderia ser assim colocada: apesar de a maioria dos membros da equipe trabalhar na saúde mental há mais de onze anos, a supervisora cedo percebeu que grande parte deles jamais teve espaço para colocar alguma pergunta sobre o que é a saúde mental, nem histórica, nem conceitualmente. Havia, na realidade, uma dificuldade no diálogo entre aqueles que poderiam esclarecer dúvidas sobre os diagnósticos clínicos e aqueles que trabalhavam com os pacientes sem nunca terem tido qualquer aula, conversa, discussão, menos ainda, formação, sobre o que é um diagnóstico, que lugar tem na história, e que função pode ter junto à direção do tratamento de um paciente - questão que se associa àquela estudada por Bezerra e Dimenstein (2008), que observaram uma precariedade na formação acadêmica dos profissionais nos CAPS por elas estudados.

A primeira providência tomada pela supervisora foi apresentar a questão, com um rápido apanhado histórico e um rápido relato do que é a psicose. Ambos foram imediatamente apreendidos pela equipe, e isso instrumentalizou enormemente as reuniões subsequentes.

Evidentemente, a dificuldade de diálogo não era decorrente de má vontade, desleixo ou qualquer falha dessa ordem por parte dos profissionais de nível superior, e, sim, da exigência de uma produção enorme, da qual o psiquiatra e as duas psicólogas dificilmente davam conta. Tendo sob suas responsabilidades mais de duzentos pacientes a serem medicados, entrevistados, com os prontuários a serem preenchidos e as justificativas para pedidos de medicação a serem despachadas, em princípio não haveria qualquer possibilidade de ainda fazer um trabalho voltado para a equipe. Assim, a supervisão funcionou como etapa decisiva, introduzindo a necessidade de um encontro semanal para esclarecimentos sobre o trabalho em equipe e o trabalho com os pacientes, e também com cada paciente que tem uma história própria, singular, articulando o geral do funcionamento do CAPS, o particular das diferentes psicopatologias e fenomenologias encontradas no dia a dia do trabalho e o singular de cada um, do paciente ao trabalhador em saúde mental, passando pelos familiares que ou frequentam o CAPS ou são visitados em seus domicílios.

Tal reunião está hoje instituída, e é realizada com todos os membros da equipe, exceto raros técnicos que, por também trabalharem em outros empregos, não têm possibilidade de virem ao encontro semanalmente. Entre os efeitos dessa mudança, é mister assinalar o 
fato de que muitas vezes se passou a trazer, para a supervisão, questões advindas dessas reuniões.

O segundo ponto a ser observado foi a forma de atuar junto aos usuários do serviço. Cedo foi percebido que a maioria dos membros da equipe se distribuem na condução de oficinas. Os que assim não fazem têm função bem estabelecida - o auxiliar administrativo é um cargo com um local de trabalho bem delineado: fica na recepção e no escritório, garantindo o funcionamento burocrático do CAPS; o psiquiatra tem a função de atender os pacientes em sua sala, e quase não dá conta da quantidade de atendimentos que precisa fazer, por isso, não tem facilidade de realizar um trabalho para além das paredes do seu consultório.

Para a surpresa da supervisora, todos os membros da equipe que não tinham uma função muito bem delineada pela própria profissão estavam necessariamente alocados em alguma oficina, eram oficineiros. Havia várias oficinas, algumas que funcionavam há muitos anos, outras, mais recentes; umas cujo trabalho promovia movimentos artísticos dos pacientes, outras em que os pacientes produziam material a ser vendido no bazar do próprio CAPS e, finalmente, algumas que surgiram mais espontaneamente; entre estas, a oficina de música - criada pelos próprios pacientes, na qual dançam ao som de discos de música romântica, o que termina por promover encontros amorosos no próprio CAPS - e a oficina do louvor, na qual usuários e membros evangélicos da equipe se associavam para rezarem juntos e cantarem hinos evangélicos. Atualmente, já não há mais essa oficina no CAPS, mas a sua existência, naquele momento, lançou luz sobre alguns dos nós críticos do serviço, de modo que podemos dizer que tal oficina era, na realidade, o efeito do encontro de várias questões que atravessavam o trabalho no CAPS - questões que diziam respeito à formação de seus técnicos e auxiliares associavam-se à primeira questão, a da falta de referências históricas e conceituais para o trabalho na saúde mental. Com efeito, havia um grande desejo de saber, nessa equipe, que ficou recalcado por muito tempo. No momento em que as perguntas sobre o que é a psicose, sobre o que leva um paciente a agir de tal modo e outro, de outro modo, e quais as determinações históricas, sociais e psíquicas para as dificuldades que os usuários do CAPS precisam enfrentar - no momento em que essas perguntas puderam começar a circular no CAPS, a resposta religiosa já não era a única possível, e passou a haver um interesse cada vez maior em saber o que se pode fazer. Além disso, começou a surgir uma consciência política do trabalho.

Listamos os primeiros resultados efetivos, para toda a equipe, das supervisões no CAPS A: 1: instalação das reuniões, também abertas aos usuários e que, portanto, muitas vezes se transformavam em assembleias, 2: criação do Projeto Terapêutico Individual, do qual cada trabalhador em saúde mental concernido participa, sabendo do que se trata em cada caso, ou seja, já não há membro da equipe que não possa saber qual é o projeto terapêutico do paciente de quem é referência ou com quem trabalha em uma oficina, pois basta perguntar ou trazer o caso para a assembleia na qual, muitas vezes, se dialetizam as propostas para o projeto terapêutico com várias contribuições, 3 : interesse em aprofundar o estudo e em saber mais alguma coisa sobre o que é a saúde mental, 4: delineamento de uma identidade de equipe, a partir de uma referência sua à história da saúde mental, de uma localização do trabalho que está sendo realizado na articulação com o trabalho de outras unidades nas quais alguns dos técnicos desse CAPS também trabalham, ou na invenção de um funcionamento surgido da experiência particular desse CAPS, diferentemente de qualquer outro serviço que se conheça, pela 
particularidade de sua própria história, 5: fim da resistência de alguns membros da equipe em se aproveitarem da nova dinâmica do CAPS para se utilizar dos diferentes canais que foram abertos com a supervisão para um diálogo com a coordenação do serviço, 6: descoberta da função política do trabalhador em saúde mental, consciência de que esse CAPS participa ativamente como promotor de um novo modo de trabalho, em nível nacional, em função de vários canais de comunicação com dispositivos do território.

\section{Um ponto de corte}

O CAPS B desde sempre se valeu de uma equipe militante e de uma coordenação forte para, encarnando seu papel de desbravador e pioneiro na região, enfrentar as adversidades políticas e os desafios da clínica na consolidação da atenção psicossocial como política pública de saúde mental para a cidade. Próximo de completar dez anos de funcionamento, ao mesmo tempo em que já não contava com pessoas - incluindo coordenadora do serviço e supervisor - cujo envolvimento no trabalho foi determinante para a sua consolidação, imprimindo uma certa marca nos modos de gestão e do fazer clínico ali postos em prática, a equipe viu diminuir o número de seus profissionais sem que se reduzisse o seu volume de trabalho.

Entre a saída de muitos e a entrada de outros, o que fôra até então construído foi colocado radicalmente em questão: o acolhimento, a assembleia, os grupos de referência, as oficinas e, ainda, a rede de serviços, a política de saúde mental e a militância no movimento antimanicomial. A equipe, sentindo-se esvaziada de recursos, não encontrava um ponto de ancoragem a partir do qual as críticas que lançava pudessem operar de forma propositiva na realidade do serviço. A situação era agravada pela aguda sensação de crise que acompanhara as transições sofridas - as saídas e entradas de profissionais, a mudança no estilo de gestão da nova coordenação e o início das funções da nova supervisora no serviço.

A supervisão trabalhou no sentido de identificar um ponto de corte possível na cadeia espiralada de questionamentos que a equipe incessantemente lançava com respeito ao trabalho em que se via imersa. Identificamo-lo nos dispositivos grupais que no serviço se ofereciam à clientela- alvo - não somente porque, dentre os temas em discussão, esses dispositivos eram os que estavam mais próximos do campo de governabilidade da própria equipe mas também pelo tipo de questionamento que, a seu respeito, ali se apresentava: mais do que buscar suprir uma oferta que se viu diminuída com a redução do número de profissionais no serviço, a equipe se perguntava sobre a importância, o sentido que, para o usuário, poderia ter o dispositivo que se oferecia, questionando-se, ainda, quanto à sua capacidade de propor e de dar sustentação a este ou a aquele dispositivo.

Os grupos de referência foram os primeiros a serem colocados em análise. Conforme os membros da equipe que acompanharam a sua constituição, o grupo de referência surgiu como resposta ao excesso de demanda do trabalho médico, de forma a descentrar a referência exclusiva e dividi-la com os demais membros da equipe, incluindo, ainda, usuários e familiares no compartilhamento de responsabilidade pelo acompanhamento de casos. Se tais coletivos permitiram organizar melhor os processos de trabalho e acompanhar de modo mais efetivo o percurso do usuário no serviço, ao mesmo tempo, vinham produzindo, como efeito não previsto e indesejável, um estancamento dos demais dispositivos e o engessamento da equipe, que, ocupando-se majoritariamente do acompanhamento desses coletivos, passava a atuar em torno da figura do médico 
- uma vez que, malgrado os seus propósitos, os grupos de referência pareciam sucumbir ao imperativo da acessibilidade ao médico. A questão não era nova para o serviço, nem específica desse CAPS, mas um dos desafios maiores a ser enfrentado no cotidiano das práticas de atenção psicossocial, ou seja, o empuxo ao engessamento e à medicalização.

Identificar essa questão para análise também abriu a possibilidade à equipe de melhor conhecer a realidade do conjunto dos usuários em atendimento no serviço - se residiam ou não naquela área de abrangência, com que frequência vinham ao serviço, se faziam ou não uso dos demais dispositivos ofertados pelo CAPS - e de otimizar as linhas de ação encampadas pela coordenação do serviço - como a visita domiciliar a usuários que se ausentavam do serviço e o encaminhamento para outros serviços daqueles que ou não eram da área de abrangência do serviço ou não demandavam o tipo de cuidados próprios de um CAPS.

\section{Costuras entre a clínica e a gestão}

Além da visão geral quanto aos seus participantes e da enunciação dos objetivos específicos de cada grupo, de seu modo de funcionamento, potencialidades e problemas, cabia aos seus coordenadores a apresentação à equipe de um caso a ele referido, pondo em evidência o modo como o dispositivo do grupo de referência interagia com os demais dispositivos em operação em um mesmo caso e possibilitando a construção coletiva do projeto terapêutico, em um trabalho em rede que buscava articular diferentes saberes no acompanhamento à singularidade do caso, sendo esse singular o que se tomava como guia a orientar a direção e o modo do cuidado.

Contudo, para além das diferentes formações, saberes e profissões de que se valia a equipe como coletivo de trabalho, algo mais se colocava em evidência no momento da construção de casos (reportamo-nos aqui à estratégia de construção do caso clínico, tal como proposta por Viganó, 1999, e retomada por Figueiredo, 2004): era a presença antagônica de duas lógicas distintas a partir das quais a atenção psicossocial era concebida, o que remetia a uma cisão indesejável entre clínica e gestão. Assim, enquanto a clínica ficava inteiramente referida à lógica de um tempo kairós, ao momento singular da emergência de um ato, acontecimento, a gestão restava prisioneira de kronos, do tempo previsível e cronometrado da busca de resultados. À supervisão, cabia o trabalho delicado, mas consistente, de costura, de tramado desses fios, de forma que clínica e gestão compusessem um mesmo tecido. A construção coletiva dos casos reportados à supervisão implicou, portanto, aplacar os antagonismos para permitir escutar o que o caso mesmo fazia falar, ponto a partir do qual, então, ambas as lógicas podiam pôr-se a conversar.

A discussão continuada em torno dos grupos de referência a cada supervisão, embora possibilitasse identificar problemas e também algumas soluções, não foi, no entanto, suficiente para operar as mudanças que se entendiam como necessárias à dinâmica do trabalho. O grupo de referência, que deveria ser meio de inserção dos usuários na rede de cuidados interna e externa ao serviço, constituíra-se em fim, retendo a circulação dos usuários e a capacidade de trabalho da equipe. Desse modo, sendo o espaço para onde de imediato eram conduzidos os novos usuários que, recebidos pelo acolhimento, ingressavam no serviço, os grupos encontravam-se superlotados, o que inviabilizava a tarefa de formular e de acompanhar o projeto terapêutico de cada um de seus participantes. Apenas uma parcela dos usuários vinha sendo de fato plenamente beneficiada pelo dispositivo. 


\section{Construção coletiva de projeto}

Diante desse quadro, chegou ao impasse a partilha de responsabilidade em relação aos novos casos acolhidos, quando a equipe de acolhimento se deparou com a recusa de um dos técnicos - médico, no caso - em receber, naquelas condições, novos usuários nos grupos de referência sob sua coordenação, o que, efetivamente, implicava uma sobrecarga do trabalho médico. Contudo, não recebê-los significava depositar essa mesma sobrecarga sobre o médico que então participava do acolhimento. A discussão tensa e indecidida que então teve lugar na equipe vinha colocar em evidência o fato de que não havia ali um projeto único de CAPS pactuado entre todos, mas talvez tantos projetos quanto profissionais, o que levou a que fosse lançada naquele momento a construção de projeto como tarefa urgente e primeira da supervisão. O trabalho teve início alternando-se as reuniões centradas na construção do projeto e aquelas em que o foco recaía sobre as situações e os casos clínicos, e contou, ainda, com a participação dos usuários e familiares, que puderam discutir os temas propostos e incluir suas sugestões. Alguns textos também serviram de subsídio nesse processo.

Ainda que se tratasse de uma atividade de planejamento, o seu fazer possibilitou à equipe sua construção como coletivo de trabalho, fazendo-a deslocar-se do lugar da queixa para o de protagonista de sua história, o que produziu alguns movimentos importantes na forma de gestão do trabalho que, com a ajuda da coordenação, foi sendo descentralizado.

Foi utilizada a metodologia, ainda que adaptada, do planejamento estratégico (Matus, 1991; Testa, 1994; Campos, 2000), que configurou as seguintes etapas do trabalho: 1) desenho do quadro atual do CAPS, 2) construção da sua imagem- objetivo, 3) levantamento de problemas e sua visualização em rede, 3) definição dos nós críticos (problemas estratégicos sobre os quais atuar) e 4) elaboração de projetos de ação para cada um dos nós críticos.

A equipe destacou dois nós críticos, que resultaram na elaboração de dois projetos de ação: projeto de construção de rede e projeto criação de dispositivos - o primeiro voltado para as ações no território, na relação com os demais serviços e outros equipamentos disponíveis na região; o segundo voltado para as ações desenvolvidas a partir do CAPS, como as oficinas, os grupos e a convivência.

A elaboração e a implantação do projeto de construção de rede produziram ações imediatas, com a intensificação de parcerias intersetoriais e supervisões conjuntas no território. Assim, para alguns dos casos acompanhados, o cuidado proposto deixou de ser tarefa exclusiva de uma equipe, tornando-se responsabilidade coletiva dos serviços do território. Já o projeto criação de dispositivos enfrentou dificuldades maiores na sua formulação e nos meios de viabilizar sua realização. Mesmo assim, apontou uma direção a imprimir às ações desenvolvidas pela equipe, produzindo já alguns movimentos na dinâmica do trabalho, como maior atenção às potencialidades do espaço aberto da convivência, intensificação do trabalho de visitas domiciliares e engajamento simultâneo de diferentes profissionais no acompanhamento coletivo de casos clínicos de alta complexidade, o que envolvia às vezes o cuidado de toda uma família ou mesmo de sua vizinhança.

\section{Elaborações finais a partir dos dois percursos de supervisão}

Colocando ambas as experiências lado a lado, chama a atenção a importância dada, pelas supervisoras, às histórias de cada um dos 
CAPS. Identificar o momento da experiência em relação ao tempo de cada um dos serviços aqui analisados, em um determinado intervalo da história de cada um, absolutamente singular, é talvez um dos fatores que mais aproxima ambas as experiências. Há uma historicidade a partir da qual situar o ponto em que se insere a tarefa da supervisão. E há uma temporalidade própria ao exercício da supervisão, a ser sustentada no cruzamento com a história de cada serviço. Em ambos os casos, essa dimensão da temporalidade se viu aguçada pelo fato de que as supervisões tinham data para terminar.

A questão tempo se apresenta não só na sincronia do percurso como também na diacronia das intervenções a cada vez que há presença do supervisor no trabalho. Em consequência, articula-se também com o que Freud (1912/1969) já especificava para toda clínica psicanalítica em 1912: ela não é possível in absentia nem in effigie, o que quer dizer que o tempo delimitado do trabalho de supervisão a partir dos contratos assim estruturados pode ou deixar a desejar ou, e aqui nos situamos, ser mais um fator a ser considerado no contexto do campo em que a psicanálise intervém na saúde mental. Dessa forma, transforma-se o próprio tempo em instrumento de interpretação e de corte, a fim de poder potencializar, com ele mesmo, a eficácia das intervenções. No lugar, então, de lastimar o curto tempo de duração do contrato de supervisão, fazemos do tempo um instrumento de trabalho com o qual toda a equipe se mobiliza, tratando de agilizar as possíveis mudanças que a presença do supervisor no CAPS pode alavancar. Em verdade, não seria a primeira vez em que o fator tempo se insere num atendimento visando a uma conclusão e levando a debates durante muitos anos: em 1918, Freud (1980) já se utilizara dessa estratégia.

Importa identificar o excesso de demanda apesar de ser impossível nos aprofundarmos aqui nessa discussão -, que recai em especial sobre o médico, indicativa de que a gestão do cuidado nesses serviços se vê diante de um impasse na busca de suplantar a lógica médico-centrada em favor de uma atenção de fato psicossocial. Observe-se que tal lógica não é necessariamente promovida pelos médicos que trabalham nesses CAPS, mas, na realidade, decorrente do modo discursivo que se pode observar nas instituições quaisquer que sejam - quando há um funcionamento agenciado pelo discurso do mestre, conforme conceituado em 19691970 por Lacan (1992), a partir da dialética hegeliana do senhor e do escravo e da teoria de Marx sobre as relações de produção no modelo capitalista, no seminário $O$ Avesso da Psicanálise: alguém ocupa o lugar do mestre (senhor) para fazer o outro (escravo) trabalhar de modo a produzir para ele, o mestre. Na medida em que há uma mão de obra excedente que ameaça o trabalhador que não faz seu trabalho conforme a exigência do mestre, este consegue se sustentar na posição de agenciador do discurso. Como dito, é mister observar que, no caso, não é necessariamente o psiquiatra que se posiciona nesse lugar de mestre; ele é ali colocado pelos outros trabalhadores, que assim tentam se desresponsabilizar por seu próprio trabalho, criticando o mestre-psiquiatra pelo modo como trabalha que, no entanto, é muitas vezes determinado apenas pelo discurso da burocracia que a institucionalização sem questionamento promove. Nesse mesmo ano de seu seminário, Lacan pôde aproximar o discurso da burocracia do discurso universitário, aquele que, justamente, joga fora o sujeito com suas questões e divisões, seus desejos e interesses particulares, promovendo o saber pelo saber a serviço do próprio capital ao qual, na realidade, o discurso universitário se dirige, sustentando a economia sem a menor consideração pelo sujeito e suas idiossincrasias. Tal fenômeno é muito visível no campo da saúde mental pelo fato de os sujeitos que o habitam já serem, de saída, marginalizados pela sociedade... não só os usuários dos serviços, 
os loucos de toda espécie - como Foucault (1978/1972) já observava a partir de seu estudo da história da loucura - mas também os próprios trabalhadores em saúde mental, que, desde sempre, foram identificados com aqueles de quem tratam - haja vista a crítica do expressionismo alemão, o Dr. Caligari ${ }^{2}$, e, antes dele, a crítica do nosso grande romancista, Machado de Assis (1882/1979), a personagem de Simão Bacamarte. Os trabalhos de supervisão aqui relatados testemunham a orientação ética da psicanálise que responsabiliza o sujeito - o próprio trabalhador em saúde mental - pelo lugar que vai ocupar nesse campo discursivo. Para tal, o discurso do psicanalista, ainda conforme Lacan, é aquele que se dirige ao sujeito, colocando-o a trabalho para que ele próprio produza o que lhe é genuíno e pelo que possa, ele mesmo, responsabilizar-se (para avançar no estudo dos discursos a partir de Lacan, sugere-se: Alberti, 2000; Castro, 2009; Quinet, s. d., entre outros).

Outra questão que atravessa ambas as experiências é o fator mudança (de Município, de gestão, de equipe), que exige um constante trabalho de atualização, o qual, por si só, já justificaria a presença de uma supervisão. Ora, o discurso do psicanalista é aquele que permite, justamente, mudanças discursivas, pois, ao se dirigir ao sujeito - no lugar do outro ao qual o psicanalista se dirige -, viabiliza que este assuma as possibilidades de mudanças. Assim, em ambos os casos aqui relatados, a supervisão sustentada no discurso do psicanalista e na ética da psicanálise abriu um espaço para que cada sujeito envolvido com os CAPs tivesse valorizada sua própria posição de sujeito, autor de um dizer.

Em ambos os CAPS, viu-se como grande contribuição das supervisões:

${ }^{2}$ Wiene, R. (Diretor) (1920). Das Kabinett des Doktor Caligari. [Filme-vídeo]. Berlim: Decla Film Company, de escuta e mediação de conflitos assumida pela supervisão, por outro, no que tange à especificidade do supervisor que também é um psicanalista, essa disponibilização do espaço da fala está fundamentalmente relacionada ao fazer falar o que não se dizia antes. Tal especificidade é muito evidente na experiência no CAPS A, em que havia nitidamente uma inibição para falar. Aos membros da equipe com formação acadêmica e experiência profissional de longos anos, não era dado o tempo necessário para poderem se comunicar entre si e com os outros membros da equipe, e os auxiliares, assistentes e profissionais de nível médio não se autorizavam a perguntar a respeito do tratamento de um caso. Além disso, auxiliares, assistentes e profissionais de nível médio podem também apresentar uma inibição de falar o que sabem a partir da experiência que trazem, diante da valorização de um saber acadêmico em detrimento do saber da prática. Dialetizar tal valorização se mostrou, então, fundamental, pois certamente o saber da experiência pode contribuir tanto - às vezes mais - quanto o saber universitário. Poderem falar abertamente sobre isso nas supervisões revelou um furo na posição de mestria que, como dito, a equipe, de maneira geral, atribuía ao psiquiatra e aos demais membros de nível superior e, concomitantemente, revelou o furo no saber da equipe como um todo, o que imediatamente mobilizou cada um da equipe a transmitir um saber tanto sobre a clínica na saúde mental quanto sobre suas políticas e história. O efeito foi imediato e influenciou, como já dito, todo o andamento do trabalho de supervisão;

2) esse processo já introduz, por si, um segundo ponto de grande contribuição em ambas as experiências: a particularidade da metodologia empregada, que resultou em construção e sistematização do saber. A especificidade do trabalho de supervisão, em especial em um CAPS, requer o assinalamento de que os supervisores em questão têm 
formação psicanalítica, são psicanalistas e pesquisam as possíveis articulações entre psicanálise e saúde mental - o que os faz visarem à transmissão possível da causa freudiana, de que a verdade se diz, mesmo se jamais é toda dita, ou seja, que é fundamental para cada membro da equipe, assim como para cada usuário, poder encontrar no campo de trabalho da saúde mental um lugar para a fala, pois é a palavra de cada sujeito que interessa nesse âmbito. Finalmente, com a valorização da fala de cada um, alavancou-se a aposta em scilicet: é possível saber, ou seja, qualquer membro de equipe de CAPS pode e quer saber, mesmo se isso nem sempre seja compreendido. Em ambas as experiências, a aposta em scilicet foi crucial para um reposicionamento das equipes;

3) em consequência disso, houve também maior entrosamento e autonomia das equipes e maior articulação com as redes em benefício do cuidado com o usuário. Construíram-se os projetos - terapêuticos, no CAPS A; coletivo, no CAPS B. Tais construções se verificaram tanto na institucionalização das assembleias no CAPS A (no CAPS B, elas já existiam) e na institucionalização das visitas a outros serviços e trabalhos conjuntos no território, em ambos os CAPS;

4) finalmente, a equipe do CAPS A assumiuse como produto, ao mesmo tempo que produtora, de sua história, enquanto o CAPS B, com o apoio de sua coordenadora, apostava na sua capacidade de fazer-se responsável pelo cuidado e pela preservação de seus espaços coletivos de decisão. $\mathrm{O}$ planejamento do CAPS, construído durante as supervisões, permaneceria como guia no trabalho, impulsionando ações, podendo ser revisto e atualizado a cada novo passo ou quando se modificasse a conjuntura, servindo ainda de parâmetro para uma avaliação do caminho andado após um certo tempo. A supervisão pôde assim alcançar, de maneira satisfatória, o seu momento de conclusão.

Mas houve também questões não elaboradas, porque nem sempre possíveis de trabalhar em supervisão. Da primeira experiência, as não poucas dificuldades individuais de alguns membros da equipe, em razão de seus próprios conflitos particulares, problema que atravessava muitas vezes as supervisões - mas que, evidentemente, não podia ser tratado ali - e que se manifestava na dificuldade de a equipe lidar com trabalhadores que apresentavam fragilidades psíquicas graves.

No que tange ao CAPS B, destacam-se as dificuldades de seus participantes cumprirem os horários previstos para a supervisão, concentrarem-se na tarefa e escutarem o outro, dificuldades reconhecidas pela própria equipe, que dizia estranhar a falta de "uma postura mais enérgica" por parte da supervisora, cujo estilo privilegiava a escuta antes que a intervenção e abstinha-se do exercício de uma função de controle junto à equipe.

As consequências de um trabalho de supervisão de CAPS na intersecção entre psicanálise e saúde mental nem sempre são mensuráveis, tanto para a equipe quanto para o supervisor, fundamentalmente, pela riqueza da experiência e pelos efeitos que pode ter para cada um. Buscamos ilustrar, aqui, o que pode um analista supervisor em um CAPS, quando efetivamente causa um trabalho na equipe.

No CAPS A, apesar de seu não raro entusiasmo com o trabalho, a equipe se via, de tempos em tempos, como que roubada de seu trabalho diante de um Outro gozador - identificado na figura do burocrata - que nada queria saber sobre as reais necessidades, demandas e desejos envolvidos em seu fazer. Porém, nas últimas supervisões, na perspectiva de mais uma mudança geográfica desse CAPS, 
a equipe pôde posicionar-se de forma diferente e, no mínimo, mais bem humorada. Há hoje um trabalho de articulação com o movimento da saúde mental que lhe dá uma inserção no campo que, se é territorial, suplanta a geografia, e isso lastreia muito mais suas ações do que uma localização geográfica que passou a ser secundária.

No CAPS B, o seu pioneirismo, somado ao histórico de militância de boa parte de seus trabalhadores, levava a equipe a encerrarse em uma posição de tudo-saber, que impossibilitava o estabelecimento de laços mais produtivos com os demais serviços de saúde e outros setores e atores de seu território bem como com a gestão e com a política de saúde mental. O exercício de suspensão desse saber, ensaiado no espaço da supervisão, possibilitou maior abertura a esses laços, levando à produção de novos saberes.

A supervisão desses CAPS permitiu a constituição de equipes cujos membros já não mais se identificavam na posição histérica do "somos os abandonados da burocracia e por isso somos contra!", ou na posição de mestre que tudo sabe e fixa o outro na posição de objeto pelo submetimento a esse saber. Sustentando uma transferência de trabalho (Alberti, 2004) nos moldes apontados por Lacan (1964/2001), viam-se, doravante, como trabalhadores de saúde mental, envolvidos com a clínica, com a política e a gestão na construção de processos coletivos no campo da atenção psicossocial. Como dito, os efeitos de uma supervisão de CAPS, mesmo quando é temporária, não podem ser calculados... são surpreendentes! Em psicanálise, a surpresa citada na teoria desde 1905 por Freud (1987) - é, na realidade, um fator da descoberta que o próprio sujeito pode fazer no momento em que lhe é dada a possibilidade de produzir um saber próprio a partir do furo do saber pré-estabelecido (leia-se, por exemplo, Freire \& Costa, 2008). Isso nem sempre é imediato, pode levar o tempo que for necessário para uma elaboração da qual o sujeito nem sempre é consciente, eis porque este texto também testemunha uma aposta que fazemos nos efeitos futuros que a prática supervisionada, a partir da psicanálise, pode promover e que os supervisores provavelmente não chegarão a conhecer.

\section{Sonia Alberti}

Pós-doutorado no Instituto de Psiquiatria da Universidade Federal do Rio de Janeiro. Professora Adjunta do Instituto de Psicologia da Universidade do Estado do Rio de Janeiro, Rio de Janeiro - RJ - Brasil.

E-mail: sonialberti@gmail.com.br

\section{Analice Palombini}

Doutora em Saúde Coletiva pela Universidade Estadual do Rio de Janeiro. Docente do Instituto de Psicologia da Universidade Federal do Rio Grande do Sul, Rio Grande do Sul - RS - Brasil.

E-mail: analicepalombini@uol.com.br

Endereço para envio de correspondência:

Rua João Afonso 60 casa 22. Rio de Janeiro - RJ - Brasil. CEP: 22261-040

Recebido 7/3/2011, 1a Reformulação 22/1/2012, Aprovado 13/4/2012. 
Alberti, S. (2004, jan./jun.) Transferência de trabalho e a universidade. Psicol. USP, 15, 1-2. Recuperado em 5 outubro, 2010 de www.scielo.br/scielo.php?script=sci_arttext\&pid $=$ S0103-65642004000100011.

Alberti, S. (2000) Psicanálise: a última flor da medicina. In S Alberti \& L. Elia (Orgs.), Clínica e pesquisa em psicanálise (pp.37-56). Rio de Janeiro: Marca d'Água Livraria e Editora Ltda.

Alberti, S., \& Figueredo, A.C. (Orgs.). (2006). Psicanálise e saúde mental, uma aposta. Rio de Janeiro: Companhia de Freud.

Bezerra, E., \& Dimenstein, M. (2008 setembro). Os CAPS e o trabalho em rede: tecendo o apoio matricial na atenção básica. Psicologia: Ciência e Profissão, 28(3), 632-645. Recuperado em 21 de de dezembro de http://pepsic.homolog.bvsalud.org/ scielo.php?.pid $=$ S1414-98932008000300015\&script $=$ sci arttext

Assis, M. de. (1979). O alienista. In A. Coutinho (Org.), Obra Completa, (Vol. II, Conto e Teatro. 4a ed., ilustrada, pp. 253288). Rio de Janeiro, Editora Nova Aguilar (Trabalho original publicado em 1882).

Campos, G. W. S., Chakour, M., \& Santos, R. C. de (1997). Análise crítica sobre especialidades médicas e estratégias para integrá-las ao Sistema Único de Saúde (SUS). Cadernos de Saúde Pública, 13(1),141-144.

Campos, G. W. S. (2000). Saúde pública e saúde coletiva: campo e núcleo de saberes e práticas. Ciênc. Saúde Coletiva (online), 5(2), 219-230 Recuperado em 21 de janeiro, 2012 de HTTP:// www.scielo.br/scielo.php?script $=$ sci_arttex\&pid $=$ S1413 $81232000000200002 \& \operatorname{lng}=\mathrm{pt \& nrm}=\overline{\text { iso }}$

Campos, R. O. (2000, jun./set.). Planejamento e razão instrumental: uma análise da produção teórica sobre planejamento estratégico em saúde, nos anos noventa, no Brasil. Cad. Saúde Pública, 16(3), 723-731.

Castro, J. E. (2009, jul./dez.). Considerações sobre a escrita lacaniana dos discursos. Ágora: Estudos em Teoria Psicanalítica, 12(2), 245-258. Recuperado em 18 de janeiro, 2012 de http://www.scielo.br/scielo.php?script=sci_arttext \&pid $=$ S1516-14982009000200006.

Figueiredo, A. C. (2004, março). A construção do caso clínico: uma contribuição da psicanálise à psicopatologia e à saúde mental. Rev. Latinoam. Psicopat. Fund., VII(1), 75-86.

Figueiredo, A. C. (2010). Três tempos da clínica orientada pela psicanálise no campo da saúde mental. In A. Guerra \& J. Moreira (Orgs.), A psicanálise nas instituições públicas. Saúde mental, assistência e defesa social. Curitiba, PR: CRV.

Foucault, M. (1978). História da loucura. São Paulo, Perspectiva (Trabalho original publicado em 1972).

Freire, A. B., \& Costa, C. A. R. (2008, jul./dez.). O literal e a surpresa: os "estágios preliminares do chiste. Ágora: Estudos em teoria psicanalítica, 11(2), 235-251. doi.org/10.1590/ S1516-14982008000200005 Recuperado em 18 de janeiro, 2012 de http://www.scielo.br/scielo.php?pid=S1516$14982008000200005 \&$ script=sci arttext.
Freud, S. (1969). A dinâmica da transferência. In Edição standard brasileira das obras psicológicas completas de Sigmund Freud - ESB - (Vol. XII, pp. 133-143, J. Salomão, trad.). Rio de Janeiro: Imago (Trabalho original publicado em 1912).

Freud, S. (1980). História de uma neurose infantil. In Edição standard brasileira das obras psicológicas completas de Sigmund Freud, (Vol. 17, pp. 19-151) (Trabalho original publicado em 1918).

Freud, S. (1987) O chiste e sua relação com o inconsciente. In Edição standard brasileira das obras psicológicas completas de Siugmund Feud - (Vol. 8, pp.13-267) (Trabalho original publicado em 1905).

Lacan, J. (2001). Acte de fondation. 21 juin 1964. In Autres écrits. Paris: Seuil (Trabalho original publicado em 1964).

Lacan, J. (1992). O Seminário, livro 17: o avesso da psicanálise (1969-1970). Rio de Janeiro: Jorge Zahar (Trabalho original publicado em 1991).

Lacan, J. (1988). O Seminário, livro 7: a ética da psicanálise (1959-1960). Rio de Janeiro, Jorge Zahar Ed. (Trabalho original publicado em 1986).

Matus, C. (1991, out./dez. ). O plano como aposta. São Paulo em Perspectiva, 5(4), 28-42.

Palombini, A. L. (2006 setembro). Acompanhamento terapêutico: dispositivo clínico-político. Psyche, 10(18), 115-127.

Palombini, A. L. (2007). Vertigens de uma psicanálise a céu aberto: a cidade. Contribuições do acompanhamento terapêutico à clínica na reforma psiquiátrica. Tese de doutorado. Programa de Pós-Graduação em Saúde Coletiva, Universidade Estadual do Rio de Janeiro, RJ. Recuperado em 21 janeiro, 2012 de http://bases.bireme.br/cgi-bin/wxislind. exe/iah/online/? IsisScript $=$ iah/iah $. x i s \& s r c=$ google $\&$ base $=$ LILACS\&lang $=p \&$ nextAction $=$ Ink\&exprSearch $=449190 \&$ indexSearch $=$ ID..

Quinet, A. (s. d.). A ciência psiquiátrica nos discursos da contemporaneidade. Recuperado em 18 janeiro, 2012 de lacanian.memory.online.fr/AQuinet_Ciencia.rtf.

Rinaldi, D. (1997, dez.). Ética e desejo: da psicanálise em intensão à psicanálise em extensão. Papéis - Revista do Corpo Freudiano, 7. Recuperado em 22 de janeiro, 2012 de www.interseccaopsicanalitica.com.br/.../Doris_Rinaldi_ Etica_desejo.d.

Rinaldi, R. \& Burstzyn, D. (2006). A reinvenção da clínica. Recuperado em 18 janeiro, 2012 de http://www. fundamentalpsychopathology.org/anais2006/4.40.3.1.htm

Testa, M. (1994). Pensamento estratégico e a lógica da programação. São Paulo: Hucitec.

Viganó, C. (set. de 1999). A construção do caso clínico em saúde mental. Revista Curinga Psicanálise e saúde mental, 13, 50-59. 